\title{
Journal of Thermal Spray Technology Volume 17 Best Paper Awards
}

The Journal of Thermal Spray Technology (JTST) is delighted to announce the winners of the JTST Volume 17 Best Paper Awards, as chosen by an international committee of expert judges. The awards were presented to the winning authors at the International Thermal Spray Conference \& Exposition 2009, in Las Vegas, Nevada.

The Editorial Committee and International Board of Review of the journal believe it is important to evaluate the quality of engineering and scientific contributions published in JTST and to provide recognition of excellent work and its publication. Each paper is reviewed and evaluated on its merits for scientific and engineering content, originality, and presentation style. The following papers are recognized as outstanding and the authors received awards of recognition for their excellent publications:

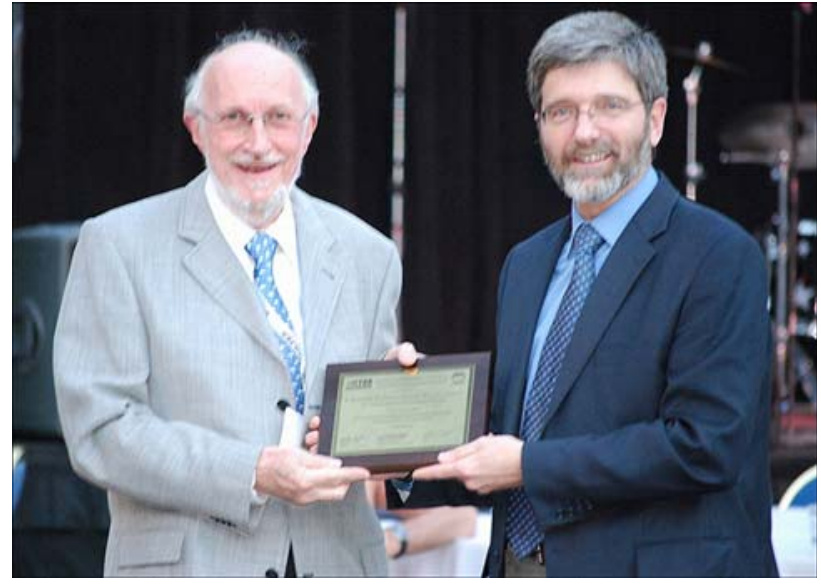

JTST Editor Christian Moreau presents the JTST Volume 17 Best Paper Award to Pierre Fauchais (left) for the paper "Parameters Controlling Liquid Plasma Spraying: Solutions, Sols, or Suspensions," which he coauthored with Ramuntxo Etchart-Salas, Vincent Rat, Jean-François Coudert, Nadège Caron, and Karine WittmannTénèze.

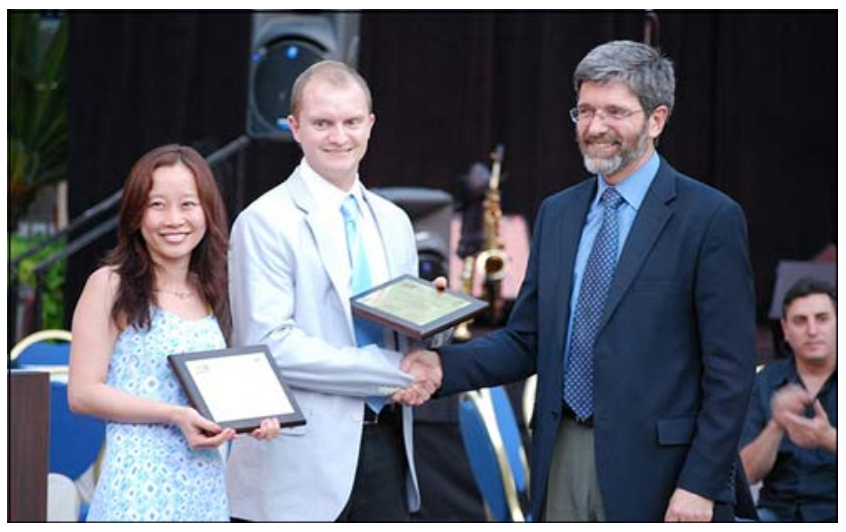

JTST Editor Christian Moreau presents the JTST Volume 17 Best Paper Award to (from left) Meng Qu and Andrew Gouldstone for their paper "On the Role of Bubbles in Metallic Splat Nanopores and Adhesion."

\section{The Journal of Thermal Spray Technology Volume 17 Best Paper Award (two papers tied for first place):}

"Parameters Controlling Liquid Plasma Spraying: Solutions, Sols, or Suspensions" by Pierre Fauchais, Ramuntxo Etchart-Salas, Vincent Rat, and Jean-François Coudert, University of Limoges; and Nadège Caron and Karine Wittmann-Ténèze, CEA le Ripault

"On the Role of Bubbles in Metallic Splat Nanopores and Adhesion" by Meng Qu, Massachusetts Institute of Technology, and Andrew Gouldstone, Northeastern University

\section{The Journal of Thermal Spray Technology Volume 17 Best Paper Honorable Mention Award:}

"Room Temperature Impact Consolidation (RTIC) of Fine Ceramic Powder by Aerosol Deposition Method and Applications to Microdevices" by Jun Akedo, National Institute of Advanced Industrial Science and Technology

Each of these three papers is an Editors' Choice article for 2008, and as such, is available as Open Access on SpringerLink.

The international committee of judges, led by Dr. Roland Seals, chair of the Journal of Thermal Spray Technology Best Paper Subcommittee, is as follows:

Arvind Agarwal, David V. Bucci, Nadège Caron, Andrew Gouldstone, Vincent Guipont, David Hart, Jan Ilavsky, Bertrand Jodoin, George Kim, Jiri Matejicek, André McDonald, Tim McKechnie, Petri Vuoristo, James A. Rudd, Philip Shipway, Tsunekawa Yoshiki, and Joel Voyer

Congratulations are extended to the winning authors from the JTST Editorial Committee and the ASM Thermal Spray Society Board of Directors. 